\title{
Óbitos por acidentes de transporte terrestre em município do noroeste do Paraná - Brasil
}

\author{
Deaths from land transport accidents in a city from Northwestern Paraná - Brazil

\section{Muertes por accidentes de tráfico en una ciudad norte occidental de Paraná - Brasil}

\author{
Meiri Vanderlei Nogueira de Lima. Secretaria Estadual de Saúde do Paraná (SESA/PR). Curitiba, PR, Brasil. nogueirameiri@gmail.com (Autora \\ correspondente) \\ Rosangela Ziggiotti de Oliveira. Universidade Estadual de Maringá (UEM). Maringá, PR, Brasil. rzo13@hotmail.com \\ Renata Bernardini de Lima. Universidade Federal de Ciências da Saúde de Porto Alegre (UFSCPA). Porto Alegre, RS, Brasil. renabl@gmail.com \\ Letícia Ziggiotti de Oliveira. Pontifícia Universidade Católica do Paraná (PUC/PR). Curitiba, PR, Brasil. leziggiotti@hotmail.com \\ Airton Pereira de Lima. Universidade Estadual de Maringá (UEM). Maringá, PR, Brasil. airtonpl@uol.com.br \\ Fernanda Nomoto Fujii. Pontifícia Universidade Católica do Paraná (PUC/PR). Curitiba, PR, Brasil. ferfujii@hotmail.com
}

\section{Resumo}

Introdução: os problemas relacionados aos acidentes de trânsito não são atributos exclusivos das grandes cidades; 0 crescimento do número de veículos circulantes, acrescido ao fato de os veículos serem incorporados no cotidiano das comunidades, faz com que até mesmo os municípios de pequeno e médio porte evidenciem nesses eventos um complexo e importante problema social. Objetivo: 0 objetivo do estudo foi 0 de descrever as características dos óbitos por acidente de transporte terrestre (ATT) no município de Cianorte-PR, no período de 2000 a 2010. Métodos: trata-se de um estudo descritivo. 0 instrumento utilizado para coleta de dados foram as declarações de óbito obtidas do Sistema de Informação de Mortalidade (SIM), incluídos nas categorias V01 a V89 do CID-10-capítulo XX. Resultados: foram estudados 224 óbitos. No ano de 2010, foi registrada a maior taxa de mortalidade (45,7/100.000 hab), e em 2008 a menor (16,7/100.000 hab). 0s homens foram 79\% ( $n=177)$ das vítimas, e a razão de sexo foi 3,7:1. A maior proporção das mortes foi no grupo de 20 a 39 anos $(n=95 ; 42 \%)$. Motociclistas, ciclistas e pedestres foram os mais vulneráveis ( $n=127$; $57 \%$; no local do acidente, ocorreram 59\% dos óbitos ( $n=132)$. Os óbitos predominaram nas rodovias ( $n=139 ; 62 \%)$, no horário das 18 às $24 \mathrm{~h}$ $(n=45 ; 34,1 \%)$ e nos finais de semana ( $n=70 ; 54 \%)$. Conclusão: os ATT configuram-se em uma questão atual de saúde dessa população. Homens adultos jovens são os mais atingidos. Idosos também são vulneráveis. Estratégias de intervenção são intensamente apresentadas na literatura, mas, no cotidiano dos serviços, isso continua um desafio a ser enfrentado.

\section{Abstract}

Introduction: problems related to traffic accidents are not only attributes of large cities but also affect small and mid-sized towns. Objective: to describe the characteristics of deaths by land transport accidents in Cianorte-PR, from years 2000 to 2010. Methods: this was a descriptive study. The instrument used for data collection were the death certificates obtained from the Mortality Information System (MIS), including deaths in categories V01-V89 ICD-10 Chapter XX. Results: we studied 224 deaths. In 2010, the highest mortality rate was registered (45.7 / 100,000 inhabitants) and the lowest was in 2008 (16.7 / 100,000 inhabitants). Men were 79\% ( $n=177)$ of the victims and the sex ratio was 3.7:1. The highest proportion of deaths were in the group of 20-39 years $(n=95 ; 42 \%)$. Motorcyclists, cyclists and pedestrians are the most vulnerable, accounting for $57 \%$ ( $n=127)$. Among the deaths, $59 \%(n=132)$ occurred at the scene. Deaths occurred predominantly on highways $(n=139 ; 62 \%)$, at the time from $6 \mathrm{pm}$ to $12 \mathrm{am}$ $(n=45 ; 34.1 \%)$ and on weekends $(n=70 ; 54 \%)$. Conclusion: land transport accidents are a current health issue for this population. More than half of the deaths are of young male adults. Seniors were also vulnerable. Intersectoral and multidisciplinary intervention strategies are strongly placed in the literature but, in everyday health services, they remain a challenge to be faced.
Palavras-chave:

Acidentes de Trânsito Coeficiente de Mortalidade Vulnerabilidade

Keywords: Accidents, Traffic Mortality Rate Vulnerability 


\section{Resumen}

Introducción: los problemas relacionados a los accidentes de tráfico no son atributos de las grandes ciudades; incluso los municipios de pequeño y medio porte evidencian en estos eventos un importante y complejo problema social. Objetivo: el objetivo del estudio fue describir las características de los decesos por accidente de transporte terrestre (ATT) en el municipio de Cianorte-PR, de 2000 a 2010. Métodos: se trata de un estudio descriptivo. El instrumento utilizado para la recolección de datos fueron las declaraciones de decesos obtenidas del Sistema de Informação de Mortalidade (SIM), incluidos en las categorías V01 a V89 - CID-10-capítulo XX. Resultados: fueron estudiados 224 decesos. En el año 2010 fue registrada la mayor tasa (45,7/100.000 habitantes) y la menor en 2008 (16,7/100.000 habitantes). Los hombres fueran 79\% ( $\mathrm{n}=177)$ de las víctimas y la razón de sexo fue 3,7:1. La mayor proporción de las muertes fue de los 20 a los 39 años ( $n=95 ; 42 \%$ ). Motociclistas, ciclistas y peatones los más vulnerables $(n=127 ; 57 \%)$; en el local del accidente ocurrieron $59 \%$ de los decesos $(n=132)$; en las carreteras, $62 \%$ ( $n=139)$; de las 18 a las 24 horas, $34,1 \%$ $(n=45)$ y en los fines de semana, $54 \%(n=70 ; 54 \%)$. Conclusión: Ios ATT se configuran como una cuestión actual de la salud de esta población. Hombres adultos y jóvenes son los más afectados. Los ancianos también son vulnerables. Estrategias de intervención son intensamente presentes en la literatura pero en el cotidiano de los servicios eso se mantiene un reto a ser afrontado.

\section{Palabras clave:}

Accidentes de Tránsito

Tasa de Mortalidad

Vulnerabilidad

\section{Introdução}

Os acidentes de transporte terrestre (ATT) são um fenômeno de abrangência mundial, relevante pela magnitude da morbimortalidade na populaçáo. Configuram-se como uma questáo atual de saúde, para a qual o instrumental cientificotecnológico é insuficiente para apontar a construção de soluçôes. Anualmente são 1,3 milhóes de mortes e de 20 a 50 milhōes de pessoas lesionadas, concentradas essencialmente em países de baixa e média renda. ${ }^{1}$ Segundo a Organização Mundial da Saúde (OMS), no ano de 2020 os acidentes de trânsito serão o segundo maior causador de anos potenciais de vida perdidos em todo o mundo. ${ }^{2}$ A estimativa da OMS para 2020 é de que o número de óbitos atinja 2,3 milhóes e se torne a sexta causa de morte em todo o mundo, cifras essas alavancadas pelos países menos desenvolvidos. ${ }^{3} \mathrm{Na}$ América Latina, a previsão é de que haja uma elevação de 154 mil mortes em 2010 para 180 mil em 2020 , um aumento de $48 \% .{ }^{4}$ O Brasil ocupa o quinto lugar entre os países com maior número de mortes no trânsito, precedido pela Índia, China, EUA e Rússia. ${ }^{5}$ A mortalidade por ATT no Brasil é a segunda mais incidente em relação ao total de mortes por causas externas, perdendo somente para os casos de agressão. ${ }^{6}$ Apesar da relevância desse tema, estudos sobre as características dos óbitos por ATT em municípios de médio porte com população de 50.000 a 100.000 hab. ${ }^{7}$ ainda sấo escassos. Como resultado, as ações de prevenção e controle criadas para redução desses eventos são insuficientes. No período de 2005 a 2010, o município de Cianorte esteve incluído entre os dez com maiores índices de vítimas por 10.000 veículos no estado do Paraná. ${ }^{8,9,10,11,12,13}$ No ano de 2010, esteve entre os dez com maior número de vítimas fatais por ATT e em $49^{\circ}$ no ranking do país. ${ }^{14}$ Os problemas relacionados aos acidentes de trânsito não são atributos exclusivos das grandes cidades; o crescimento progressivo do número de veículos circulantes, acrescido da incorporação de veículos no cotidiano das comunidades faz com que até mesmo os municípios de pequeno e médio porte populacional evidenciem nesses eventos um complexo e importante problema social. O objetivo deste estudo foi o de descrever as características dos óbitos por ATT no município de Cianorte-PR, no período de 2000 a 2010.

\section{Material e métodos}

Trata-se de um estudo descritivo sobre a mortalidade por ATT no município de Cianorte-PR. A cidade localiza-se a noroeste do estado e, segundo o censo do IBGE de 2010, conta com uma população de 69.958 habitantes. O instrumento utilizado para coleta de dados foram as declaraçôes de óbito obtidas do Sistema de Informação de Mortalidade (SIM), junto ao setor de Vigilância Epidemiológica da $13^{\text {a }}$ Regional de Saúde de Cianorte/SESA no período proposto para estudo. Na declaração de óbito, são informadas as características relativas ao tempo, pessoa, lugar e às condiçôes básicas associadas ao evento. Incluíram-se na pesquisa os óbitos codificados na CID (Classificação Internacional de Doenças), hoje na 10a revisão, capítulo XX, "Causas externas de mortalidade e morbidade", especificados em categorias que variam de V01 a V99. Para obter informações sobre as vítimas fatais de trânsito, foram analisadas as mortes nas categorias V01 a V89, pois as restantes incluem acidentes de transporte que não são objeto desta pesquisa (por água, aéreo e outros não especificados). As variáveis utilizadas para o estudo foram: faixa etária, sexo, local do óbito (hospital, via pública e outros), local do acidente (zona urbana, rodovias e local não especificado), horário do acidente e dia da semana (só para os óbitos ocorridos no próprio local do acidente) e condição da vítima (ocupante/condutor; motociclista, ciclista, pedestre e outros (carroceiro e não especificados). O estudo foi aprovado pelo comitê de ética do Hospital do Trabalhador de Curitiba-PR, em março de 2012. Para análise, as variáveis foram apresentadas sob a forma de valores absolutos e relativos. Foram efetuados cálculos da razão de sexo e coeficientes. Os dados foram analisados pelos programas Epi Info versão 3.4.3. 


\section{Resultados}

Para obter informaçóes sobre as vítimas fatais de trânsito, foram analisadas as mortes nas categorias V01 a V89. A taxa de mortalidade no período estudado foi de 32,2/100.000 habitantes. O maior coeficiente de mortalidade ocorreu em 2010 (45,7/100.000 habitantes) e o menor, em 2008 (16,7/100.000 habitantes) (Figura 1).

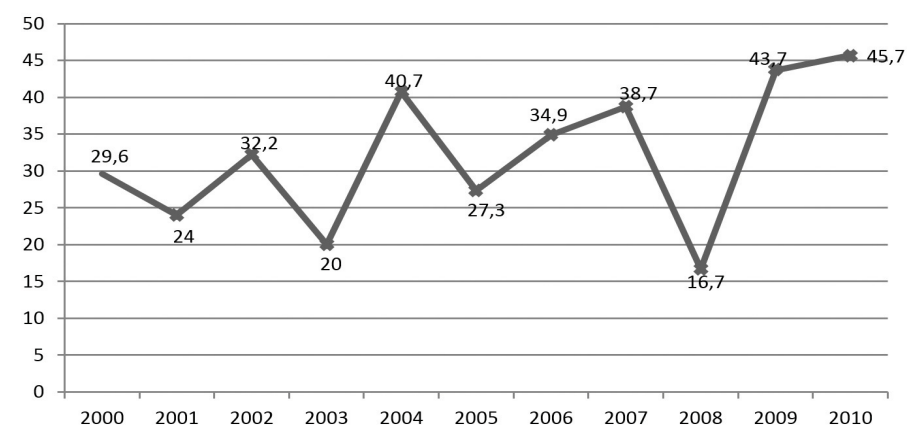

Figura 1. Coeficientes de mortalidade por ATT (por 100.000 hab). Cianorte-PR. 2000 a 2010.

Fonte: Sistema de Informação de Mortalidade/13aRS/Epidemiologia.

Com relação ao sexo, os coeficientes de mortalidade da população masculina foram superiores ao feminino em todo período estudado; observou-se redução em ambos no ano de 2008 (Figura 2).

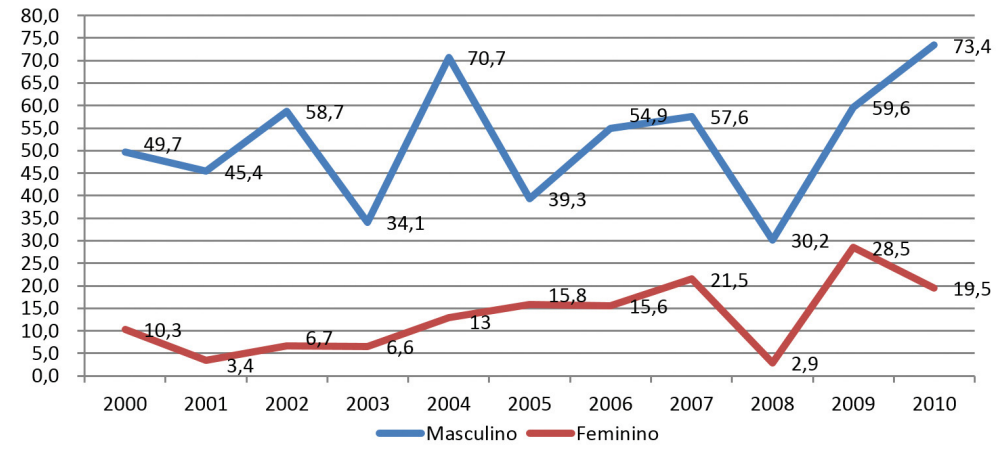

Figura 2. Coeficientes de mortalidade (por 100.000 habitantes) por acidente de transporte terrestre segundo o sexo. Cianorte-PR, 2000-2010. Fonte: Sistema de Informação de Mortalidade/13aRS/Epidemiologia.

A Tabela 1 apresenta os óbitos por grupo etário. A população masculina representou $79 \%(\mathrm{n}=177)$ dos óbitos, e os grupos etários mais atingidos foram os dos 20 aos 39 anos, com 42,4\% (n=95). A razão masculino/feminino foi de 3,7:1.

Tabela 1. Óbitos por acidente de transporte terrestre segundo grupo etário, sexo e razão de sexo. Cianorte, Paraná, Brasil, de 2000 a 2010.

\begin{tabular}{|c|c|c|c|c|c|c|c|}
\hline \multirow{3}{*}{ Grupo etário } & \multicolumn{4}{|c|}{ Sexo } & \multirow{2}{*}{\multicolumn{2}{|c|}{ Total }} & \multirow{3}{*}{$\begin{array}{c}\text { Razão de sexc } \\
\text { M/F }\end{array}$} \\
\hline & \multicolumn{2}{|c|}{ Masculino } & \multicolumn{2}{|c|}{ Feminino } & & & \\
\hline & $\mathrm{N}$ & $\%$ & $\mathrm{n}$ & $\%$ & $\mathrm{~N}$ & $\%$ & \\
\hline $0-14$ anos & 10 & 5,6 & 3 & 6,4 & 13 & 5,8 & $3,3: 1$ \\
\hline $15-19$ anos & 18 & 10,2 & 9 & 19,1 & 27 & 12,1 & $2,0: 1$ \\
\hline $20-29$ anos & 43 & 24,3 & 6 & 12,8 & 49 & 21,9 & $7,1: 1$ \\
\hline $30-39$ anos & 38 & 21,5 & 8 & 17,0 & 46 & 20,5 & $4,7: 1$ \\
\hline $40-49$ anos & 24 & 13,5 & 6 & 12,8 & 30 & 13,4 & $4,1: 1$ \\
\hline 50 - 59 anos & 15 & 8,5 & 9 & 19,1 & 24 & 10,7 & $1,6: 1$ \\
\hline 60 ou mais & 29 & 16,4 & 6 & 12,8 & 35 & 15,6 & $4,8: 1$ \\
\hline Total & 177 & 100 & 47 & 100 & 224 & 100 & $3,7: 1$ \\
\hline
\end{tabular}

Fonte: Sistema de Informação de Mortalidade/13aRS/Epidemiologia. 
Observa-se que a faixa dos grupos 20 a 29 e de 30 a 39 anos representou 42,4\% ( $\mathrm{n}=95)$ dos óbitos e a razão masculino/ feminino acentuou-se dos 20-29 anos (7,1:1). Com relação à condição da vítima, ocupantes-condutores totalizaram 80 (35,7\%); motociclistas, 72 (32,1\%); pedestres, 36 (16,1\%); ciclistas, $19(8,5 \%)$ e outros, 17 (7,5\%). A Tabela 2 apresenta os óbitos segundo o grupo e a condição da vítima.

Tabela 2. Óbitos por acidente de transporte terrestre segundo o grupo etário e a condição da vítima - Cianorte, Paraná, Brasil de 2000 a 2010.

\begin{tabular}{|c|c|c|c|c|c|c|c|c|c|c|}
\hline \multirow{2}{*}{ Grupo etário } & \multicolumn{2}{|c|}{ Ocupante/Condutor } & \multicolumn{2}{|c|}{ Motociclista } & \multicolumn{2}{|c|}{ Ciclista } & \multicolumn{2}{|c|}{ Pedestre } & \multicolumn{2}{|c|}{ Outros } \\
\hline & $\mathrm{N}$ & $\%$ & $\mathrm{n}$ & $\%$ & $\mathrm{n}$ & $\%$ & $\mathrm{n}$ & $\%$ & $\mathrm{n}$ & $\%$ \\
\hline $0-14$ anos & 4 & 5,0 & 0 & 0,0 & 3 & 15,8 & 6 & 16,7 & 0 & 0,0 \\
\hline $15-19$ anos & 7 & 8,8 & 17 & 23,6 & 2 & 10,5 & 0 & 0,0 & 1 & 5,9 \\
\hline $20-29$ anos & 18 & 22,5 & 26 & 36,1 & 0 & 0,0 & 1 & 2,8 & 4 & 23,5 \\
\hline $30-39$ anos & 20 & 25,0 & 17 & 23,1 & 4 & 21,1 & 2 & 5,6 & 3 & 17,6 \\
\hline $40-49$ anos & 14 & 17,5 & 8 & 11,1 & 2 & 10,5 & 3 & 8,3 & 3 & 17,6 \\
\hline $50-59$ anos & 9 & 11,3 & 3 & 4,2 & 5 & 26,3 & 5 & 13,9 & 2 & 11,8 \\
\hline 60 ou mais & 8 & 10,0 & 1 & 1,4 & 3 & 15,8 & 19 & 52,8 & 4 & 23,5 \\
\hline Total & 80 & 100 & 72 & 100 & 19 & 100 & 36 & 100 & 17 & 100 \\
\hline
\end{tabular}

Fonte: Sistema de Informação de Mortalidade/13ªRS/Epidemiologia.

No município estudado, 57\% ( $\mathrm{n}=127)$ das vítimas de ATT incluíam-se na condição de motociclista, pedestre ou ciclista. No grupo das pessoas com menos de 15 anos $(n=13)$, composto por dez meninos e três meninas, nove eram ciclistas ou pedestres. No grupo etário de 60 anos e mais, 52,8\% (n=19) eram pedestres. Com relaçáo ao grupo dos 20 aos 29 anos, observou-se que predominaram as mortes de motociclistas e foi este o grupo etário que apresentou a maior razão de sexo encontrada no estudo $(7,1: 1)$. A Tabela 3 apresenta os óbitos segundo o local do acidente, local do óbito, horário e dias da semana. As variáveis horário e dia da semana são somente para os óbitos ocorridos no próprio local do acidente. Os óbitos por ATT ocorreram especialmente nas rodovias, 62\% $(n=139)$.

Tabela 3. Óbitos por acidente de transporte terrestre segundo local do acidente, local do óbito, horário e dias da semana* Cianorte-PR, Brasil de 2000 a 2010

\begin{tabular}{lcc}
\hline \multicolumn{1}{c}{ Variáveis } & N & $\%$ \\
\hline Local do acidente & 45 & 20,0 \\
Zona Urbana & 139 & 62,0 \\
Rodovias Federais, Estaduais e Municipais & 40 & 18,0 \\
Local não especificado & & \\
Local do óbito & 90 & 40,0 \\
Hospital & $132^{*}$ & 59,0 \\
Via Pública & 2 & 1,0 \\
Outros & & \\
Horário do acidente* & 29 & 22,0 \\
00:01 - 06:00 & 21 & 15,9 \\
06:01 - 12:00 & 30 & 22,7 \\
12:01 - 18:00 & 45 & 34,1 \\
18:01 - 24:00 & & \\
Dia da semana* & 11 & 8,3 \\
Segunda & 6 & 4,5 \\
Terça & 13 & 9,8 \\
Quarta & 10 & 7,6 \\
Quinta & 22 & 16,7 \\
Sexta & 36 & 27,3 \\
Sábado & 34 & 25,8 \\
Domingo & & \\
*óbitos ocorridos no local do acidente & & \\
\hline Fonte: Sistema lnformacão de Mortalidal13*RS/Ep & \\
\hline
\end{tabular}

Fonte: Sistema de Informação de Mortalidade/13aRS/Epidemiologia. 
Quanto ao local do óbito, 59\% (132) ocorreram nas vias públicas no próprio local do acidente. Com relação ao horário do acidente, observou-se que eles se concentraram das 18 às 24 horas (34,1\%). Em 7 declaraçóes de óbito (5,3\%) o horário não foi informado. Quando se observam os dias da semana, encontra-se que 53\% ( $\mathrm{n}=70)$ dos ATT ocorreram nos sabádos e domingos, sendo que a partir de sexta-feira essa proporção eleva-se para 70\% ( $n=92)$.

\section{Discussão}

Morais Neto et al. ${ }^{15}$ analisaram a variação de taxas de acidentes de transporte segundo porte populacional dos municípios no país e evidenciaram que entre 2000 e 2010 o risco de morte por ATT apresentou maior elevaçáo nos municípios com até 20.000 habitantes e nos de 20.000 a 100.000 . O estudo apontou vários municípios no estado do Paraná, em Santa Catarina e alguns de Sáo Paulo que fazem fronteira com o Paraná como aglomerados de maior risco de mortes por ATT no país por todos os tipos de vítimas. Esse aglomerado é formado por 474 municípios e totaliza uma populaçáo de 12.356.353 habitantes, sendo a taxa de mortalidade, de 27,4/100.000 habitantes, ${ }^{15}$ inferior à encontrada no presente estudo. O município de Cianorte está inserido neste aglomerado de maior risco.

Observou-se que no ano de 2008 a taxa de mortalidade foi a menor encontrada; isso pode ser atribuído à implantação da Lei 11.705, denominada "Lei Seca", que entrou em vigor em junho desse mesmo ano. Mello Jorge e Koizum ${ }^{16}$ mostraram que houve impacto imediato na mudança de comportamento em relação à bebida/direção e redução das internaçóes hospitalares e óbitos no país, porém, semelhante ao encontrado no presente estudo, não houve efeito continuado. Em Londrina-PR, uma pesquisa realizada por Teixeira et al. ${ }^{17}$ com vítimas de ATT registradas pelo Sistema de Informaçáo sobre Acidente de Trânsito (SIAT) evidenciou uma redução do número de óbitos fatais nos seis meses posteriores à implantação da lei quando comparado aos seis meses anteriores. Andreuccetti et al. ${ }^{18}$, em estudo realizado entre 2001 e 2010, concluíram que, no estado de São Paulo, a "lei seca" brasileira teve um impacto maior sobre as mortes no trânsito do que sobre as lesóes, com um efeito maior na capital, onde presumivelmente o policiamento foi reforçado.

Duarte et al. ${ }^{19}$ relatam que o desenvolvimento econômico pode inicialmente levar a um aumento do número de óbitos por acidentes de transporte em razão da circulação de um maior número de veículos a motor sem o suficiente estabelecimento de mecanismos de adaptação a esse crescimento. Acrescenta-se ainda o aumento da frota de veículos, a insuficiente fiscalização, a precariedade de transporte público e a infraestrutura inadequada como fatores também implicados na violência urbana. ${ }^{15}$ O crescimento da frota de veículos no município de Cianorte foi identificado em todo período, de tal forma que, do ano de 2005 a 2010, houve um acréscimo de $51,9 \% .^{12,13}$

O envolvimento substancial da população masculina nas mortes violentas encontrado no estudo segue uma realidade mundial e sabe-se que essa sobremortalidade tem impacto negativo sobre a expectativa de vida do homem. Conforme dados do Global Burden of Disease Study em 2004, os ATT foram responsáveis por 14\% das mortes dos homens e 5\% das mulheres. ${ }^{20}$ Uma pesquisa realizada no Brasil por Bacchieri e Barros, ${ }^{21}$ observando os anos de 1998 a 2010, mostrou a predominância da população masculina nos óbitos numa razão de 4,5:1, número superior ao encontrado no presente estudo. Choquehuanca et al..$^{22}$ referem que a vulnerabilidade masculina aos ATT é frequentemente atribuída à pressão exercida pelo grupo, imaturidade, sentimento de onipotência aliado ao excesso de álcool, alta velocidade e à imprudência do condutor.

Na população norte-americana, entre 1999 e 2003, as taxas de acidentes fatais foram maiores para os motociclistas, pedestres e ciclistas. ${ }^{23} \mathrm{O}$ relatório mundial da OMS de 2004 citou que a maioria das mortes ocorridas nos países em desenvolvimento atinge principalmente pedestres, ciclistas e motociclistas, considerados os usuários mais vulneráveis do sistema viário, especialmente quando se levam em conta as políticas de prevenção. ${ }^{24}$ Estudo de Chandran et al. ${ }^{25}$ entre 2000 e 2008 concluiu que os usuários vulneráveis estáo contribuindo numa proporçáo crescente para a fatalidade dos acidentes

de trânsito no Brasil. Isso está de acordo com o encontrado no presente estudo, no qual se observou que 57\% ( $\mathrm{n}=127)$ das vítimas de ATT incluíam-se na condição de motociclista, pedestre ou ciclista.

Quando se observa o grupo etário com relação à condição da vítima, evidencia-se maior vulnerabilidade dos menores de 14 e dos maiores de 60 anos ao atropelamento. O predomínio dos meninos pode estar relacionado à maior liberdade para brincar na rua, por vezes até perto de rodovias, e para ir sozinho à escola bem antes das meninas; essa maior vigilância para com elas poderia, portanto, resultar em uma maior proteção. No Brasil, em 2009, os ATT representaram a primeira causa de morte na populaçáo de dez a 14 anos. ${ }^{26}$ Em consonância aos dados encontrados na literatura, o presente estudo também 
evidenciou que os indivíduos homens acima de 60 anos foram os mais expostos. O estudo de Souza et al. ${ }^{27}$ evidenciou que a incidência de atropelamentos atinge duas a três vezes mais a população idosa masculina do que a feminina. $\mathrm{O}$ envolvimento de pedestres acima de 60 anos em atropelamentos graves reflete a redução na percepção e na agilidade, a diminuição da acuidade visual, um maior hábito de caminhar do que de dirigir e um maior envolvimento em atividades comunitárias. ${ }^{28}$

Pesquisas realizadas no país por Andrade e Melo Jorge $\mathrm{e}^{29} \mathrm{e}$ Montenegro et al. ${ }^{30}$ evideciaram que a proporção de motociclistas entre as vítimas de ATT é relevante, variando de 30\% a 50\%, dado semelhante ao encontrado neste estudo (32,1\%). Embora as motocicletas ocupem o espaço urbano como eficientes ferramentas de transporte e trabalho diante do trânsito congestionado das grandes cidades, observa-se também que, mesmo nas cidades de pequeno e médio porte, essa realidade não é diferente. $\mathrm{O}$ incremento da frota de motocicletas, o aumento de veículos por habitantes e a vulnerabilidade dos motociclistas provavelmente justificam esse perfil. No município do estudo, de 2005 a 2010, a frota de motocicletas também registrou um acréscimo de $69,3 \% .^{12,13}$

Com relação aos ciclistas, evidenciam-se no país números crescentes de óbitos: em 2005, foram mais de 1.500 mortes e, em 2008, mais de 1.600. ${ }^{21,25}$ Os ciclistas representaram no estudo 8,5\% dos óbitos. Embora no município existam ciclovias, elas são afastadas da zona urbana e não privilegiam os trabalhadores que as utilizam como meio de transporte. A construção de espaços exclusivos para a circulação de bicicletas (ciclovias e ciclofaixas) nas cidades é a principal sugestão para aumentar a segurança desses usuários, aliada ao conhecimento da população em relação às leis de trânsito. ${ }^{21}$

A mortalidade dos residentes do município de Cianorte concentrou-se nas rodovias. Minayo ${ }^{6}$ refere que as mortes por acidentes acontecem sobretudo nas localidades cortadas por vias expressas, onde há estradas em má conservação e intenso movimento, e no interior das cidades em crescimento. $\mathrm{O}$ município em questão ocupa uma posiçấo relevante no estado do Paraná. Trata-se de um polo localizado na regiáo noroeste, forte no setor agrícola, comercial, industrial e com destaque nacional na indústria do vestuário. Um dos principais acessos que ligam a cidade a outras localidades é uma rodovia estadual, com intenso tráfego de veículos, que faz a rota norte-oeste paranaense e uma das poucas não pedagiadas. Este trajeto é utilizado por camioneiros para desvio de pedágios. Além disso, no perímetro urbano, há um percurso que é utilizado por veículos, especialmente pesados, que ligam a regiâo central do estado com a divisa do Mato Grosso do Sul. Essas condiçôes certamente contribuem para as altas taxas de mortalidade por ATT encontradas no município.

Quanto ao local do óbito, 59\% (132) ocorreram nas vias públicas no próprio local do acidente. Isso evidencia, além da gravidade do acidente, a importância dos serviços de emergência estarem prontamente disponíveis e instrumentalizados para o adequado atendimento dos eventos. Um estudo realizado por Fey et al. ${ }^{31}$ entre 2004 e 2006 no Alto Vale do Itajaí-SC refere que $72 \%$ dos acidentes com vítimas fatais ocorreram nas rodovias e $62 \%$ foram a óbito no local do acidente. Um levantamento realizado no país de 1996 a 2005 identificou que, no último ano investigado, do total de acidentes no trânsito, $7 \%$ terminaram em óbitos e $71 \%$ ocorreram no próprio local do acidente. ${ }^{32}$

Com relação ao horário, observou-se que eles se concentraram das 18 às 24 horas (34,1\%). Achados semelhantes foram encontrados no estudo realizado em Olinda-PE nos anos de 2006-200733 e no Alto Vale do Itajaí. ${ }^{31}$ Em Londrina-PR, Bastos et al. ${ }^{34}$, e em Maringá-PR, Scalassara et al. ${ }^{35}$ observaram que as maiores concentraçóes dos ATT ocorreram de tarde e à noite. É possível que a concentraçáo dos acidentes fatais nesse horário sofra influência do maior fluxo de veículos que se acumula no retorno do trabalho, fato aliado ao cansaço físico e mental, à diminuição da visibilidade e às condiçóes das vias públicas.

Quando se estudam os ATT segundo os dias da semana, a concentração acontece especialmente aos sábados e domingos $(n=70 ; 54 \%)$, sendo que a partir de sexta-feira essa proporção eleva-se para $70 \%(n=92)$. Isso sugere que o consumo de álcool e de outras substâncias psicoativas é outro fator que pode se adicionar à maior ocorrência dos ATT nos finais de semana. Achados semelhantes foram observados em estudo realizado em Londrina-PR por Bastos et al..$^{34}$ e em Maringá-PR por Scalassara et al. ${ }^{35}$,cidades localizadas próximas ao município estudado. Isso reforça os achados da literatura que citam a maior ocorrência de acidentes de trânsito e de vítimas fatais nos finais de semana. ${ }^{36,37,38}$

Embora não objeto deste estudo, é interessante ressaltar que, além da mortalidade, existe o impacto da morbidade causada pelos ATT, que implica em aumento da demanda dos profissionais da atenção primária para o cuidado daqueles com sequelas dos acidentes (paraplégicos, tetraplégicos, amputados ou com dor crônica), o que torna esses agravos mais dispendiosos para o sistema público de saúde e para a sociedade como um todo. Além disso, os profissionais de atençáo primária prestam assistência aos familiares que se apresentam enlutados, entristecidos e deprimidos pelas perdas. 
A magnitude dessas mortes na população masculina deve levar a uma reflexão sobre a adequação das atuais políticas de saúde do homem, que priorizam a vulnerabilidade para o desenvolvimento do câncer de próstata, em dissonância com os princípios do SUS, que propóem o olhar da integralidade.

Como principal limitação deste estudo, citamos a utilização de dados secundários, que muitas vezes não são preenchidos ou são digitados incorretamente, embora nos últimos anos seja perceptível a melhoria das informaçóes do SIM da região.

\section{Conclusão}

Os achados do estudo retratam especificidades de óbitos por ATT em município de médio porte. Os adultos jovens e os homens foram os mais atingidos, com mais da metade dos óbitos. Em outro extremo da vida, os idosos também mostraram-se vulneráveis. Estratégias de intervenção amplas, intersetoriais e multiprofissionais são intensamente colocadas na literatura, mas, na prática dos serviços de saúde, dada à sua complexidade, não parecem tão simples de serem delineadas. Por outro lado, reconhece-se que com uma abordagem integral do indivíduo e da família, ao identificar sua vulnerabilidade, os profissionais das equipes de saúde podem contribuir na prevenção desses eventos.

\section{Referências}

1. World Health Organization (WHO). Global status report on road safety: time for action. Geneva: WHO; 2009 [acesso em 2012 Jun 20 ]. Disponível em: http://www.who.int/violence_injury_prevention/road_safety_status/2009.

2. Murray CJ, Lopez A. The global burden of disease: a comprehensive assessment of mortality and disability from diseases, injuries and risk factors in 1990 and projected to 2020. Cambridge: Harvard University; 1996. (The global burden of disease and injury series, vol 1).

3. World Health Organization (WHO). Global status report on road safety 2013: supporting a decade of action. Geneva: WHO; 2013 [acesso em 2013 Mar 15]. Disponível em: http://www.who.int/violence_injury_prevention/road_safety_status/2013/report/en/index.html.

4. World Health Organization (WHO). Mejoramiento de la seguridad vial en el mundo. Geneva: WHO; 2011 [acesso em 2013 Mar 15]. Disponível em: http://www.who.int/roadsafety/about/resolutions/sept_2011_sg_report_es.pdf.

5. World Health Organization (WHO). Informe sobre la situación mundial de la seguridad vial. Geneva: WHO; 2009 [acesso em 2013 Mar 15]. Disponível em: http://www.who.int/violence_injury_prevention/road_safety_status/data/table_a2es.pdf.

6. Minayo MCS. Seis características das mortes violentas no Brasil. Rev Bras Est Pop. 2009;26(1):135-140. Disponível em: http://dx.doi.org/10.1590/S0102-30982009000100010.

7. Instituto Brasileiro de Geografia e Estatística (IBGE). Censo Demográfico de 2010 [Internet]. [acesso em 2012 May 20]. Disponível em: http://www.ibge.gov.br/home/estatistica/populacao/censo2010.

8. Secretaria de Estado da Segurança Pública (PR), Departamento de Trânsito, Divisão de Estatística. Anuário estatístico 2005. Paraná; 2005 [acesso em 2012 Feb 25]. Portuguese. Disponível em: http://www.detran.pr.gov.br/arquivos/File/estatisticasdetransito/anuario2005.pdf.

9. Secretaria de Estado da Segurança Pública (PR), Departamento de Trânsito, Divisão de Estatística. Anuário estatístico 2006. Paraná; 2006 [acesso em 2012 Feb 25]. Portuguese. Disponível em: http://www.detran.pr.gov.br/arquivos/File/estatisticasdetransito/anuario2006.pdf.

10. Secretaria de Estado da Segurança Pública (PR), Departamento de Trânsito, Divisão de Estatística. Anuário estatístico 2007. Paraná; 2007 [acesso em 2012 Feb 25]. Portuguese. Disponível em: http://www.detran.pr.gov.br/arquivos/File/estatisticasdetransito/anuario2007.pdf.

11. Secretaria de Estado da Segurança Pública (PR), Departamento de Trânsito, Divisão de Estatística. Anuário estatístico 2008. Paraná; 2008. [acesso em 2012 Feb 25]. Portuguese. Disponível em: http://www.detran.pr.gov.br/arquivos/File/estatisticasdetransito/anuario2008.pdf.

12. Secretaria de Estado da Segurança Pública (PR), Departamento de Trânsito, Divisão de Estatística. Anuário estatístico 2009. Paraná; 2009. [acesso em 2012 Feb 25]. Portuguese. Disponível em: http://www.detran.pr.gov.br/arquivos/File/estatisticasdetransito/anuario/2009/anuario2009.pdf.

13. Secretaria de Estado da Segurança Pública (PR), Departamento de Trânsito, Divisão de Estatística. Anuário estatístico 2010. Paraná; 2010. [acesso em 2012 Feb 25]. Portuguese. Disponível em: http://www.detran.pr.gov.br/arquivos/File/estatisticasdetransito/anuario/anuario2010.pdf.

14. Waiselfisz JJ. Mapa da violência 2012. Os novos padrões da violência homicida no Brasil. São Paulo: Instituto Sangari; 2012.

15. Morais Neto OL, Montenegro MMS, Monteiro RA, Siqueira Jr JB, Silva MMA, Lima CM, et al. Mortalidade por acidentes de transporte terrestre no Brasil na última década: tendência e aglomerados de risco. Ciênc Saúde Coletiva. 2012;17(9):2223-2236. Disponível em: http://dx.doi.org/10.1590/S1413-81232012000900002.

16. Mello Jorge MHP, Koizum MS. Acidentes de trânsito causando vítimas: possível reflexo da lei seca nas internações hospitalares. Rev ABRAMET. 2009;27(2):16-25. Disponível em: http://producao.usp.br/handle/BDPI/13441.

17. Teixeira RJ, Calixto R, Pinheiro ACD. O reflexo da lei seca nos acidentes de trânsito em Londrina. In: Peixe BCS, Müller CC, Hilgemberg CMAT, Melatti GA, Bertolini GRF, Machado HPV, et al., editors. Formulação e gestão de políticas públicas no Paraná: reflexões, experiências e 
contribuições. Curitiba: Editora Progressiva; 2008 [acesso em 2012 Jun 20]. Vol 1. p. 457-475. Disponível em http://www.escoladegoverno.pr.gov.br/arquivos/File/formulacao_e_gestao_de_politicas_publicas_no_parana/volume_Il/capitulo_4_seguranca_ publica/4_11.pdf.

18. Andreuccetti G, Carvalho HB, Cherpitel CJ, Ye Y, Ponce JC, Kahn T, et al. Reducing the legal blood alcohol concentration limit for driving in developing countries: a time for change? Results and implications derived from a time-series analysis (2001-10) conducted in Brazil. Addiction. 2011;106(12):2124-31. Disponível em: http://dx.doi.org/10.1111/j.1360-0443.2011.03521.x.

19. Duarte EC, Tauil PL, Duarte E, Sousa MC, Monteiro RA. Mortalidade por acidentes de transporte terrestre e homicídios em homens jovens das capitais das Regiões Norte e Centro-Oeste do Brasil, 1980-2005. Epidemiol Serv Saúde. 2008 [acesso em 2012 Feb 25];17(1):7-20. Disponível em: http://scielo.iec.pa.gov.br/scielo.php?script=sci_arttext\&pid=S1679-49742008000100002\&lng=en\&nrm=iso.

20. Patton GC, Cofey C, Sawyer SM, Viner RM, Haller DM, Bose K, et al. Global patterns of mortality in young people: a systematic analysis of population health data. Lancet. 2009;374:881-892. Disponível em: http://dx.doi.org/10.1016/S0140-6736(09)60741-8.

21. Bacchieri G, Barros AJD. Acidentes de trânsito no Brasil de 1998 a 2010: muitas mudanças e poucos resultados. Rev Saúde Pública. 2011;45(5):949-963. Disponível em: http://dx.doi.org/10.1590/S0034-89102011005000069.

22. Choquehuanca-Vilca V, Cardenas-Garcia F, Collazos-Carhuay J, Mendoza-Valladolid W. Perfil epidemiológico de los accidentes de tránsito en el Perú, 2005-2009. Rev Peru Med Exp Salud Publica. 2010 [acesso em 2012 Feb 25];27(2):162-169. Disponível em: http://www.scielo.org.pe/scielo.php?script=sci_arttext\&pid=S1726-46342010000200002\&lng=es\&nrm=iso.

23. Beck LF, Dellinger AM, O'Neil ME. Motor vehicle crash injury rates by mode of travel, United States: using exposure-based methods to quantify differences. Am J Epidemiol. 2007;166(2):212-8. Disponível em: http://dx.doi.org/10.1093/aje/kwm064.

24. Gawryszewski VP, Coelho HMM, Scarpelini S, Zan R, Jorge MHPM, Rodrigues EMS. Perfil dos atendimentos a acidentes de transporte terrestre por serviços de emergência em São Paulo, 2005. Rev Saúde Pública. 2009;43(2):275-282. Disponível em: http://dx.doi.org/10.1590/S0034-89102009000200008.

25. Chandran A, Sousa TRV, Guo Y, Bishai D, Pechansky F. Road traffic deaths in Brazil: rising trends in pedestrian and motorcycle occupant deaths. Traffic Inj Prev. 2012;13(Supp1):11-16. http://dx.doi.org/10.1080/15389588.2011.633289.

26. Mascarenhas MD, Monteiro RA, Sá NNB, Gonzaga LAA, Neves ACM, Roza DL, et al. Epidemiologia das causas externas no Brasil: mortalidade por acidentes e violências no período de 2000 a 2009. In: Ministério da Saúde (BR). Saúde no Brasil 2010: uma análise da situação de saúde e de evidências selecionadas de impacto de ações de vigilância em saúde. Brasília: Ministério da Saúde; 2011 [acesso em 2013 Mar 15]. Chapter 11, p. 225-249. Disponível em: http://bvsms.saude.gov.br/bvs/publicacoes/saude_brasil_2010.pdf.

27. Souza RKT, Soares DFPP, Mathias TAF, Andrade OG, Santana RG. Idosos vítimas de acidentes de trânsito: aspectos epidemiológicos e impacto na sua vida cotidiana. Acta Sci. Health Sci. 2003;25(1):19-25. Disponível em: http://dx.doi.org/10.4025/actascihealthsci.v25i1.2247.

28. Organização Pan-Americana da Saúde. Seguranca de pedestres: manual de seguranca viária para gestores e profissionais da área. Brasilia: OPAS; 2013. Disponível em: http://apps.who.int/iris/bitstream/10665/79753/7/9789275718117_por.pdf

29. Andrade SM, Mello Jorge MH. Características das vitimas por acidente de transporte terrestre em município da Região Sul do Brasil. Rev Saúde Pública. 2000;34(2):149-156. Disponível em: http://dx.doi.org/10.1590/S0034-89102000000200008.

30. Montenegro MMS, Duarte EC, Prado RR, Nascimento AF. Mortalidade de motociclistas em acidentes de transporte no Distrito Federal, 1996 a 2007. Rev Saúde Pública. 2011;45(3):529-538. Disponível em: http://dx.doi.org/10.1590/S0034-89102011000300011.

31. Fey A, Bahten LCV, Becker IC, Furlani LF, Teixeira João VC, Teixeira Jair VC. Perfil epidemiológico dos óbitos em acidentes de trânsito na região do Alto Vale do Itajaí, Santa Catarina, Brasil. ACM Arq Catarin Med. Jan-Mar 2011;40(1):23-27.

32. Mello Jorge MHP, Koizumi MS. Acidentes de trânsito no Brasil: um atlas de sua distribuição. Rev ABRAMET. 2008;26(1):52-58. Disponível em: http://producao.usp.br/handle/BDPI/13445.

33. Cabral APS, Souza WV, Lima MLC. Serviço de Atendimento Móvel de Urgência: Um observatório dos acidentes de transportes terrestre em nível local. Rev Bras Epidemiol. 2011;14(1):03-14. Disponível em: http://dx.doi.org/10.1590/S1415-790X2011000100001.

34. Bastos YGL, Andrade SM, Soares DA. Características dos acidentes de trânsito e das vítimas atendidas em serviço pré-hospitalar em cidade do Sul do Brasil, 1997/2000 Cad Saúde Pública. 2005;21(3):815-822. Disponível em: http://dx.doi.org/10.1590/S0102-311X2005000300015.

35. Scalassara MB, Souza RKT, Soares DFPP. Características da mortalidade por acidentes de trânsito em localidades da região Sul do Brasil. Rev Saúde Pública. 1998;32(2):125-32. Disponível em: http://dx.doi.org/10.1590/S0034-89101998000200004.

36. Andrade SM, Mello Jorge MHP. Acidentes de transporte terrestre em município da Região Sul do Brasil. Rev Saúde Pública. 2001;35(3):318-320. Disponível em: http://dx.doi.org/10.1590/S0034-89102001000300017.

37. Mauro MLF. Acidentes de trânsito: perfil epidemiológico de vítimas e caracterização de alguns traços de personalidade de motoristas infratores em Campinas [tese]. São Paulo: Universidade Estadual de Campinas; 2001. 610 p.

38. Abreu AMM; Lima JMB. Silva LM. Níveis de alcoolemia e mortalidade por acidentes de trânsito na cidade do Rio de Janeiro. Esc Anna Nery Rev Enferm. 2007;11(4):575-580. Disponível em: http://dx.doi.org/10.1590/S1414-81452007000400003. 